\title{
Mutant Huntingtin induces activation of the Bcl-2/adenovirus E1B 19-kDa interacting protein (BNip3)
}

\author{
J Sassone ${ }^{1,6}$, C Colciago ${ }^{1,2,6}$, P Marchi ${ }^{3}$, C Ascardi ${ }^{1,4}$, L Alberti ${ }^{5}$, A Di Pardo ${ }^{3}$, R Zippel ${ }^{2}$, S Sipione ${ }^{3}$, V Silani ${ }^{1,7}$ and A Ciammola ${ }^{\star, 1,7}$
}

Huntington's disease (HD) is a neurodegenerative disorder characterized by progressive neuronal death in the basal ganglia and cortex. Although increasing evidence supports a pivotal role of mitochondrial dysfunction in the death of patients' neurons, the molecular bases for mitochondrial impairment have not been elucidated. We provide the first evidence of an abnormal activation of the Bcl-2/adenovirus E1B 19-kDa interacting protein 3 (BNip3) in cells expressing mutant Huntingtin. In this study, we show an abnormal accumulation and dimerization of BNip3 in the mitochondria extracted from human HD muscle cells, HD model cell cultures and brain tissues from HD model mice. Importantly, we have shown that blocking BNip3 expression and dimerization restores normal mitochondrial potential in human HD muscle cells. Our data shed light on the molecular mechanisms underlying mitochondrial dysfunction in HD and point to BNip3 as a new potential target for neuroprotective therapy in HD.

Cell Death and Disease (2010) 1, e7; doi:10.1038/cddis.2009.6; published online 14 January 2010

Subject Category: Neuroscience

This is an open-access article distributed under the terms of the Creative Commons Attribution License, which permits distribution and reproduction in any medium, provided the original author and source are credited. Creation of derivative works is permitted but the resulting work may be distributed only under the same or similar license to this one. This license does not permit commercial exploitation without specific permission.

Huntington's disease (HD) is a neurodegenerative disorder caused by a poly-glutamine (poly-Q) expansion in the protein known as Huntingtin (htt). The neurons of HD patients progressively die as the disease progresses, leading to widespread atrophy of the striatum and cortex, which account for the clinical symptoms of the disease.

Studies on the central nervous system (CNS) and peripheral tissues of HD patients, as well as in animal and cell culture models of HD, have identified several mitochondrial abnormalities, including a decreased activity of respiratory chain enzymatic complexes, a decreased ATP/ADP ratio and an altered morphology of these organelles. ${ }^{1-5}$ Mitochondria have an essential role in the physiology of eukaryotic cells; not only do they produce most of the cell's ATP but they also participate in ion homeostasis, regulation of the cell's redox state, lipid and amino-acid metabolism, as well as in regulation of programmed cell death. All these functions are highly dependent on the mitochondrial electrochemical transmembrane potential $\left(\Delta \psi_{\mathrm{m}}\right)$, a physicochemical parameter consisting of two components, namely the total transmembrane electrical potential (voltage gradient) and the proton gradient that is physiologically generated across the inner mitochondrial membrane by the activity of the respiratory chain. Growing evidence indicates that the many mitochondrial abnormalities observed in HD tissues may stem from an abnormal $\Delta \psi_{\mathrm{m}}$, as the mitochondria extracted from HD patients had $\Delta \psi_{\mathrm{m}}$ values lower than the mitochondria from normal patients. ${ }^{6-9} \Delta \psi_{\mathrm{m}}$ loss seems to be a direct effect of mutant htt, given that it occurs in normal cells transfected with mutant htt ${ }^{10,11}$ and when mutant htt is added to mitochondria isolated from normal brains. ${ }^{12}$

The results from these studies notwithstanding, the molecular bases for the $\Delta \psi_{\mathrm{m}}$ decrease observed in HD cells still remain elusive.

Bcl-2/adenovirus E1B 19-kDa interacting protein 3 (BNip3) is a member of the so-called BH3-only subfamily of $\mathrm{Bcl}-2$ family proteins that regulate the permeability state of the outer mitochondrial membrane (OMM). This regulation is accompanied by the formation of homo- and hetero-oligomers inside the membrane, which influences $\Delta \psi_{\mathrm{m}}$ and controls cell death mechanisms. ${ }^{13,14}$ The BNip3 protein is normally present in the brain tissue and skeletal muscle ${ }^{15}$ and is mainly localized in the cytoplasm and nucleus or is found loosely associated with the mitochondrial membrane in an inactive conformation. ${ }^{16,17}$

The molecular mechanism underlying BNip3 activation is not completely understood, but it probably involves a multi-

\footnotetext{
${ }^{1}$ Department of Neurology and Laboratory of Neuroscience, Centro 'Dino Ferrari' Università degli Studi di Milano - IRCCS Istituto Auxologico Italiano, Milano, Italy; ${ }^{2}$ Department of Biomolecular Sciences and Biotechnology, Università degli Studi di Milano, Milano, Italy; ${ }^{3}$ Department of Pharmacology, University of Alberta, Edmonton, Canada; ${ }^{4}$ Department of Structural and Functional Biology and Center for Neuroscience, Università dell' Insubria, Varese, Italy and ${ }^{5}$ Unit of Metabolic Diseases and Diabetes - IRCCS Istituto Auxologico Italiano, Milan, Italy

*Corresponding author: A Ciammola, Department of Neurology and Laboratory of Neuroscience, IRCCS Istituto Auxologico Italiano, via Spagnoletto 3, Milan 20149, Italy. Tel: + 003902619112 937; Fax: +02619 112 937; E-mail: a.ciammola@auxologico.it

${ }^{6}$ These authors contributed equally to this work.

${ }^{7}$ These authors are the co-last authors.

Keywords: Huntington's disease; mitochondria; BNip3

Abbreviations: $\mathrm{HD}$, Huntington's disease; htt, Huntingtin; BNip3, Bcl-2/adenovirus E1B 19-kDa interacting protein 3; $\Delta \psi_{\mathrm{m}}$, mitochondrial membrane potential; OMM, outer mitochondrial membrane; YAC, yeast artificial chromosome; WB, western blot; siRNA, short interfering RNA; PK, proteinase-K; CNS, central nervous system Received 18.9.09; revised 15.10.09; accepted 15.10.09; Edited by G Melino
} 
step process. A few intracellular toxic stimuli, such as decreased intracellular $\mathrm{pH}$ and increased cytosolic calcium concentration, ${ }^{17,18}$ can induce BNip3 integration into the OMM with the protein's $\mathrm{N}$ terminus in the cytoplasm and $\mathrm{C}$ terminus inside the mitochondria. ${ }^{19}$ The BNip3 C-terminal hydrophobic domain is required for integration in the OMM, as its deletion prevents the mutant protein (BNip3 $\Delta T M)$ from integrating into the $\mathrm{OMM}$ and inducing cell death. ${ }^{20,21}$ Importantly, BNip3 $\Delta \mathrm{TM}$ functions as a dominant-negative mutant, interacting with wild-type BNip3 and blocking its integration into the OMM. ${ }^{22-24}$ Once integrated into the OMM, BNip3 can self-associate and form stable homodimers on the basis of intermonomeric helix-helix polar interactions of various side chains. ${ }^{25}$ The unique structure of the transmembrane domain suggests that BNip3 dimers could function as proton channels in the OMM, thereby increasing ion conductance. ${ }^{25}$

Considering the crucial role of BNip3 in regulating OMM permeability, we have undertaken a study to investigate the potential role of $\mathrm{BNip3}$ in the mitochondrial dysfunction induced by mutant htt.

\section{Results}

Increased BNip3 levels and mitochondrial localization in muscle cells from HD patients. We have previously shown that myoblasts isolated from HD patients show mitochondrial dysfunction. ${ }^{8}$ To investigate the potential role of BNip3, we analyzed its expression levels in muscle cell lysates from four HD and four control subjects by SDS-PAGE. The molecular weight of BNip3, as predicted from its amino-acid sequence, is $21.5 \mathrm{kDa}$; however, the protein has been described to migrate as two major molecular species, with apparent molecular weights of $\sim 30$ and $\sim 60 \mathrm{kDa}$ in SDS-PAGE gels, representing monomeric and dimeric forms, respectively. ${ }^{26,27}$ The apparent molecular weight of monomeric BNip3 in SDS-PAGE and the presence of multiple protein bands at $\sim 30 \mathrm{kDa}$ are likely due to protein phosphorylation, as BNip3, similar to many proteins of the Bcl-2 family, bears consensus sites for phosphorylation by protein kinases (Supplementary Figure 1). ${ }^{18}$ The biological role of these possible posttranslational modifications still remains unknown. The BNip3 signal at $\sim 60 \mathrm{kDa}$, corresponding to BNip3 dimers, can be detected by SDS-PAGE, as BNip3 dimers are highly stable and resistant to detergents. ${ }^{26,28}$

In cell lysates from human HD myoblasts, we detected monomeric BNip3. Densitometric analysis showed higher levels of monomeric BNip3 in HD myoblasts than in myoblasts extracted from control subjects. Dimeric BNip3 was barely detectable in total lysates of human myoblasts (Figure 1a).

As the pivotal step in BNip3-mediated cell death involves its integration into the $\mathrm{OMM},{ }^{19}$ we tested whether the increased expression of BNip3 resulted in increased mitochondrial localization. Mitochondria-enriched fractions were prepared from normal and HD human muscle cells and then treated by alkaline $\mathrm{pH}$. This treatment detaches loosely associated peripheral membrane proteins, thus enriching the samples for mitochondrial transmembrane proteins. ${ }^{29}$ Immunoblot analysis of alkali-treated mitochondrial fractions showed strong monomeric BNip3 signals in both HD and control myoblasts. However, there was a trend of increased monomeric BNip3 in HD samples. The dimeric form of BNip3 was visible only in the HD mitochondria and was not detectable in control myoblasts (Figure 1b). HD myoblasts derived from patients carrying 60 CAG repeats (lane 6) had the highest dimeric BNip3 signal.

To confirm the increased association of BNip3 with the HD mitochondria, we performed confocal microscopy on myoblasts obtained from control and HD patients. Notably, BNip3 colocalized with the mitochondria in $\sim 40 \%$ of HD cells, while the protein was mainly localized in the cytoplasm and in the nucleus in control cells (Figure 1c and Supplementary Figure 2).

Overall, our data suggest the accumulation and dimerization of BNip3 protein in the mitochondria of human HD muscle cells.

BNip3 levels in the brain tissue from R6/2 and YAC128 mouse models. To investigate whether the changes observed in BNip3 expression and localization in muscle cells obtained from HD patients mirrored events occurring in the CNS, we analyzed BNip3 levels and localization patterns in the brain tissues of two different HD model mice, namely $\mathrm{R} 6 / 2$ and yeast artificial chromosome (YAC)128. R6/2 mice are transgenic for exon-1 of the human IT15 gene, containing highly expanded CAG repeats, ${ }^{30}$ whereas YAC128 mice express a full-length IT15 gene with 128 CAG repeats. ${ }^{31}$ There was a trend of decreased monomeric BNip3 in HD striatum samples (Figure 2a); no significant difference in BNip3 expression was observed in the cortex from R6/2 and littermate control mice at 10 weeks of age (Figure $2 b$ ). It is noteworthy that immunoblotting analysis of alkali-treated mitochondrial fractions showed a stronger dimeric BNip3 signal in the $\mathrm{R} 6 / 2$ striatum than in the wild-type striatum (Figure $2 \mathrm{c}$ ). In $\mathrm{R} 6 / 2$ mitochondrial fractions, we also observed an anti-

Figure 1 Analysis of BNip3 expression and BNip3 integration into the mitochondrial membranes of human myoblasts. (a) Equal protein amounts from control (lanes 1-4) and HD myoblasts (lanes 5-8) were analyzed by WB and probed with anti-BNip3 antibody (Clone ANa40, Sigma). The signal corresponding to monomeric BNip3 was higher in HD myoblasts (from left to right: 48, 60, 42and 42 CAG, sample numbers correspond to the subject numbers in Supplementary Table 1) than in control myoblasts. Lane 9 was a positive control (control myoblasts transfected with the plasmid encoding BNip3 protein). Equal protein loading was verified by stripping and reprobing membranes with antiactin antibody. Protein band densitometry is reported in the corresponding graphs as means \pm S.E.M. $\left({ }^{*} P<0.05\right)$. (b) Mitochondria-enriched fractions from control (lanes $\left.1-4\right)$ and HD myoblasts (lanes 5-8) were analyzed by WB. To verify equal protein loading, membranes were stripped and reprobed with anti-COX IV antibodies. Protein band densitometry is reported in the corresponding graphs as means \pm S.E.M. Dimeric BNip3 signal was clearly detectable in HD myoblasts (from left to right: $48,60,42$ and 42 $\mathrm{CAG}$ ). There was a trend toward increased monomeric BNip3 in $\mathrm{HD}$ samples $(P=0.056)$. (c) Confocal microscopy on myoblasts isolated from control and $\mathrm{HD}$ subjects. White arrows indicate regions of extended BNip3 and mitochondrial colocalization in $\mathrm{HD}$ myoblasts. The image is representative of four myoblast cultures from four $\mathrm{HD}$ patients. Line scans below the images indicate colocalization between BNip3 (green) and mitochondria (red) and correlate with the lines drawn in the images 
BNip3-immunoreactive band with an apparent molecular weight $>60 \mathrm{kDa}$, which is consistent with previously described higher-order oligomeric forms of $\mathrm{BNip} 3 .^{14,32}$
Immunoblotting analysis of cortical mitochondrial fractions showed a slight increase in the dimeric BNip3 signal in the $R 6 / 2$ striatum than in the wild-type striatum, a
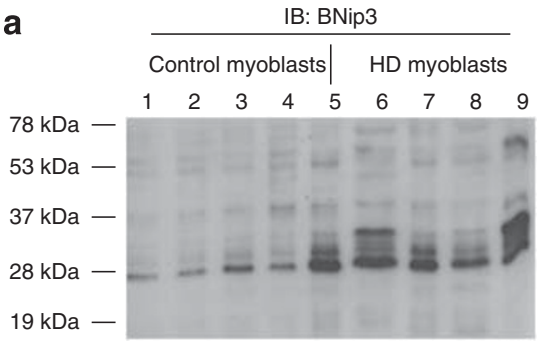

IB: Actin

$-m-m-m-m=$

b
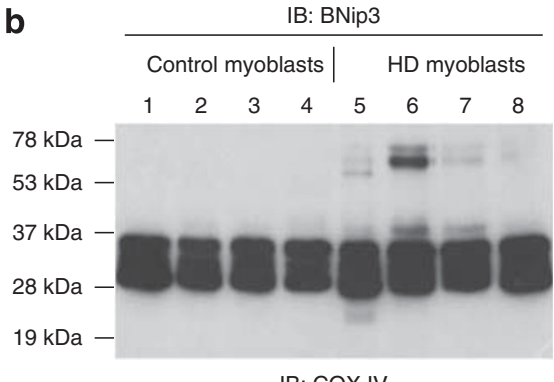

$\longleftarrow$ dimeric form

IB: COX IV

$\infty-\infty-\infty-$

C
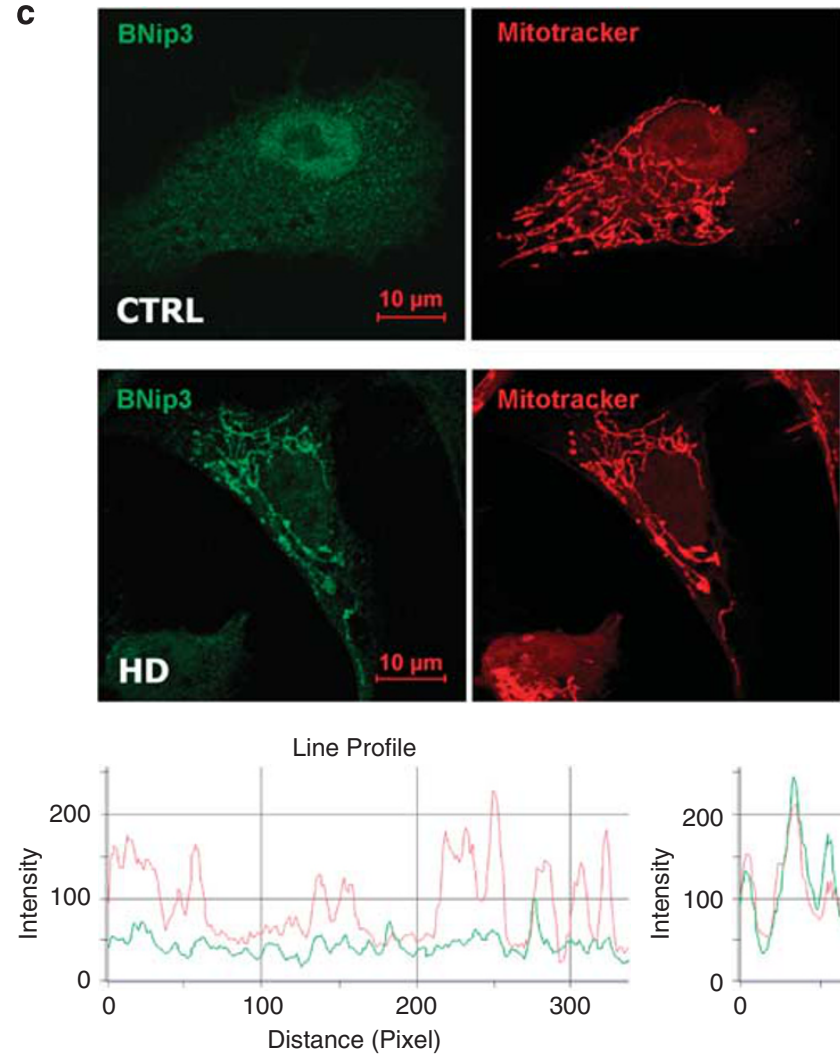

Control myoblasts
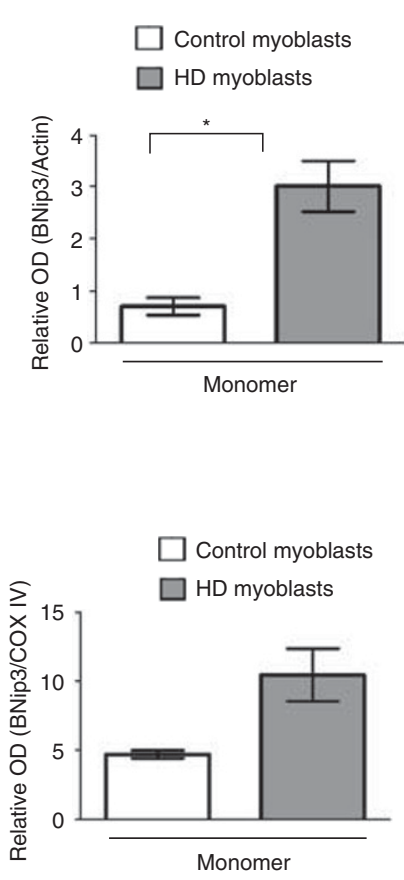
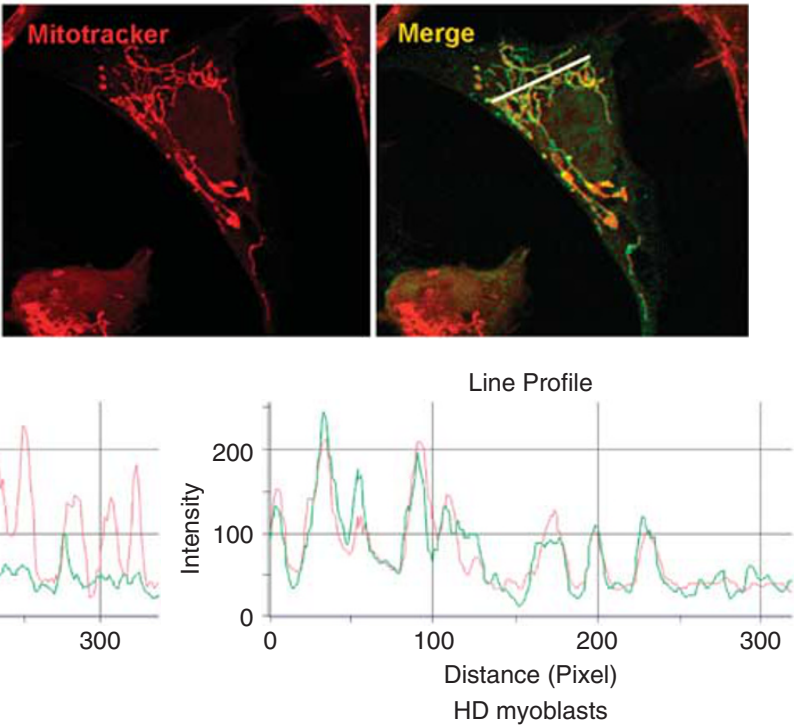
but the difference did not reach statistical significance (Figure 2d).

In the striatum of 6-month-old YAC128 mice, levels of monomeric and dimeric BNip3 were significantly increased with respect to control littermates (Figure 2e). Expression levels in the cortex showed a high degree of variability among the animals analyzed, and mean differences between control and HD mice did not reach statistical significance (Figure $2 \mathrm{f}$ ). However, the variance in the distribution of BNip3 levels in the HD group was significantly different from the variance in the control group of animals, suggesting a trend toward increased BNip3 levels in HD cortexes. Similar to R6/2 animals, the mitochondria from the YAC128 striatum contained more BNip3 than those from the control striatum (Figure 2g). No difference in BNip3 level was detected between the YAC128 cortical mitochondria and the mitochondria from control cortexes (Figure $2 \mathrm{~h}$ ).

Expression of mutant htt induces the accumulation of monomeric BNip3, BNip3 dimerization and BNip3 integration into the OMM in HD cell culture models. To investigate whether the observed alteration of BNip3 levels in $\mathrm{HD}$ myoblasts and HD mouse models was the direct result of mutant htt expression, we transfected the neuroblastoma cell line, SHSY5Y, with a plasmid encoding exon-1 of wildtype (SHSY5Y-htt-wt) or mutant (SHSY5Y-htt-mut) htt (Figure 3a). Immunoblotting analysis of whole-cell lysates showed that mutant htt caused an accumulation of monomeric and dimeric BNip3 (Figure 3b, line 3).

To investigate whether mutant htt expression also promoted BNip3 integration into the mitochondrial membrane, we isolated mitochondria from SHSY5Y-htt-wt and SHSY5Y-httmut cells and treated them with alkali. Under these conditions, significant amounts of BNip3 dimers and oligomers were detectable in the mitochondria from SHSY5Y-htt-mut cells, but not from cells transfected with normal htt (Figure 3c).

To further confirm that mutant htt induced BNip3 integration into mitochondrial membranes, we analyzed an additional model cell line. HEK293T cells express barely detectable levels of endogenous BNip3 under normal growth conditions; ${ }^{33}$ therefore, we conducted cotransfection experiments of the plasmid encoding htt, together with the plasmid encoding BNip3.

As a negative control, we transfected the mutant BNip3 $\Delta T M$, which lacks the C-terminal domain essential for integration into the OMM. At $72 \mathrm{~h}$ after transfection, wild-type a

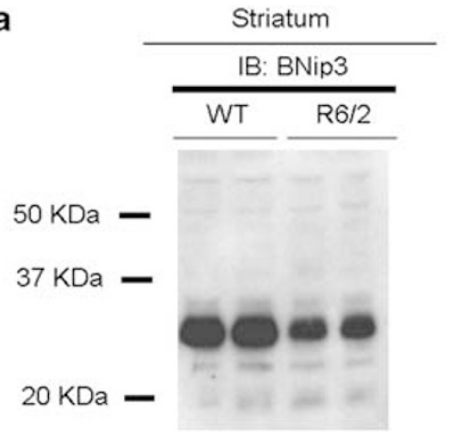

IB: Actin
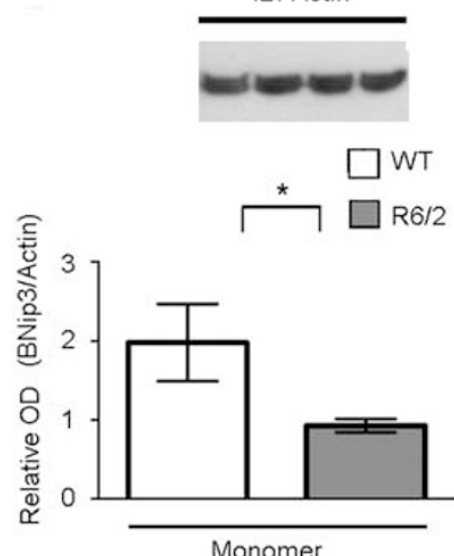

b

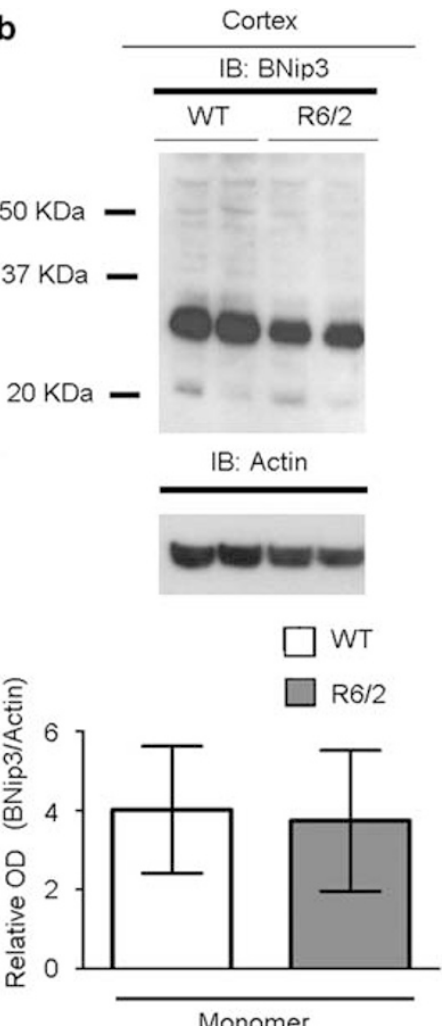

Figure 2 Analysis of the BNip3 level and BNip3 integration into the mitochondrial membrane in the brains of R6/2 and YAC128 mice. (a, b) Whole-protein lysates of the striatum (left panel) and cortex (right panel) from 10-week-old R6/2 and littermate control mice were analyzed by WB, using anti-BNip3 antibodies. There was a trend toward decreasing monomeric BNip3 in the R6/2 striatum ( ${ }^{\star} P<0.05$ ). No statistically significant difference in total BNip3 expression between R6/2 and wild-type mice was detected in cortical tissues. Data are representative of six R6/2 and six wild-type mice. (c, d) The panels show WB analysis of alkali-treated mitochondrial fractions from the striata and cortexes of 10-week-old R6/2 and control mice. To verify equal protein loading, membranes were stripped and reprobed with an anti-TOM20 antibody. Data are representative of the six R6/2 and six wild-type mice analyzed $\left({ }^{*} P<0.05\right)$. (e, f) Immunoblotting and densitometric analysis of BNip3 expression in total lysates from the striatum (left panel) and cortex (right panel) samples of five 6-month-old YAC128 mice and control littermates. Each lane represents one individual animal. Protein band densitometry results are reported in the corresponding graphs as means \pm S.E.M. (two-tailed $t$-test, $\left.{ }^{\star} P<0.05\right)$. (g, h) The panels show immunoblotting and densitometric analysis of BNip3 in alkalitreated mitochondrial fractions from the striata and cortexes of $\mathrm{YAC1} 28$ and control mice. TOM20 was used as a loading control (two-tailed $t$-test, ${ }^{*} P<0.05$ ) 
C
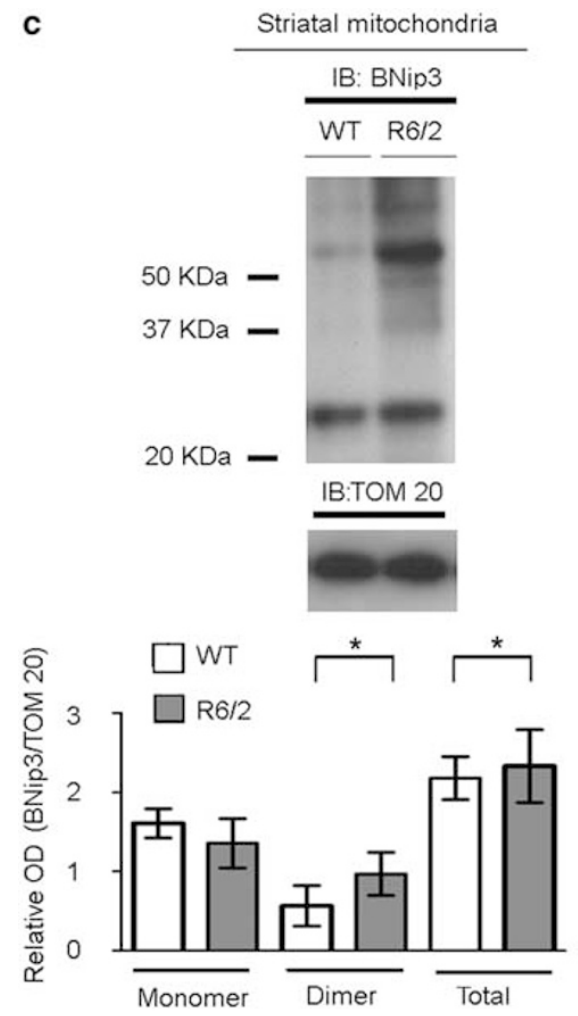

e
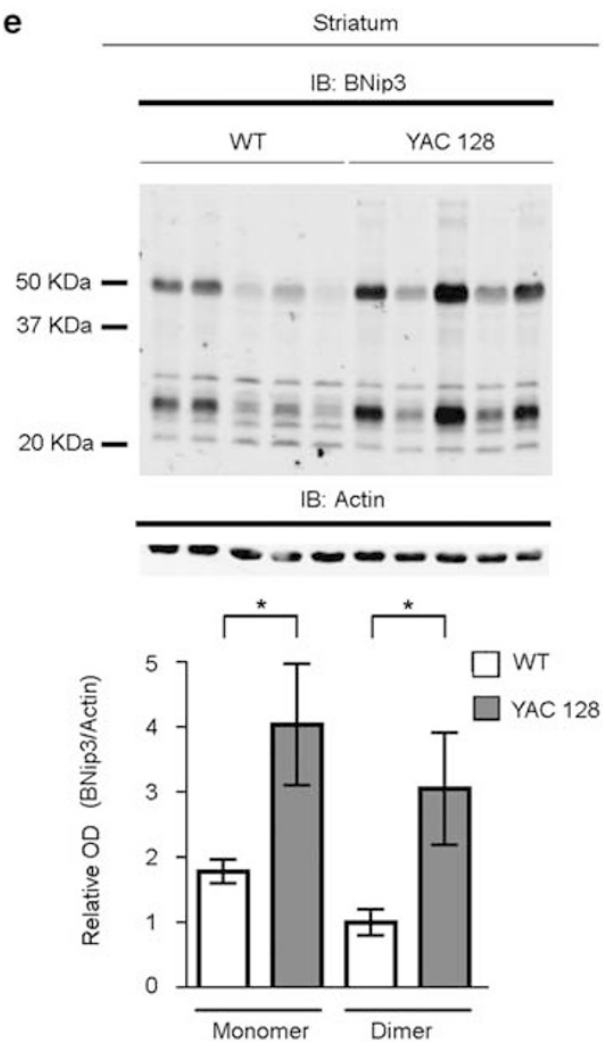

d

Cortical mitochondria
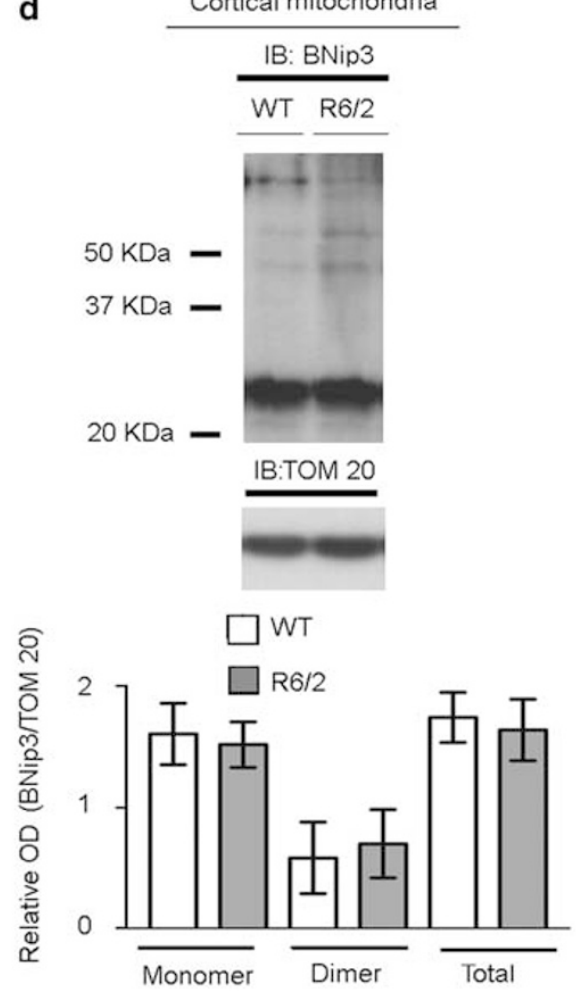

f

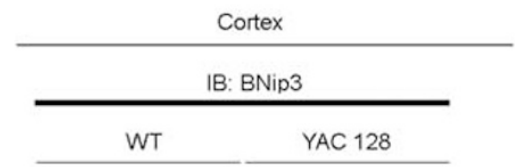

$20 \mathrm{KDa}-$
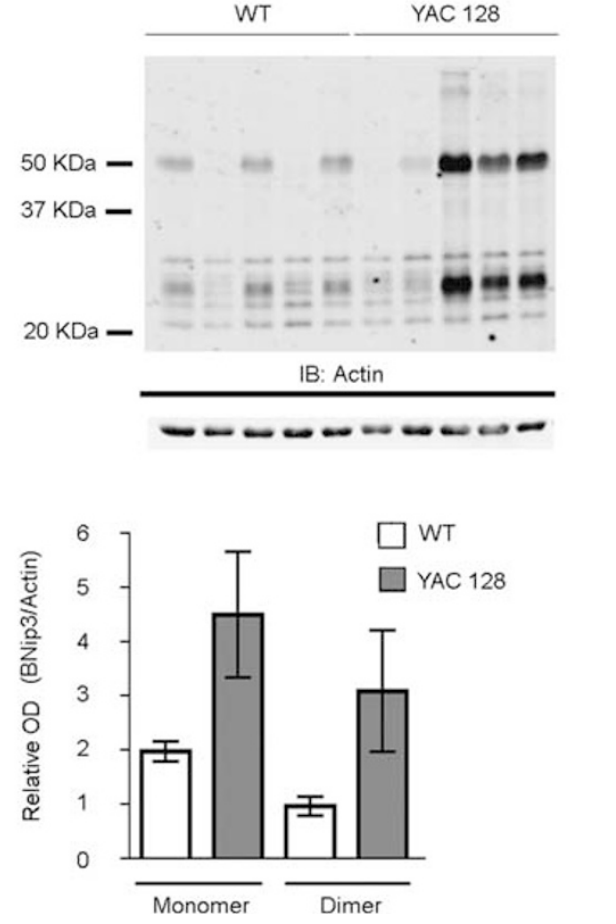

Figure 2 Continued 

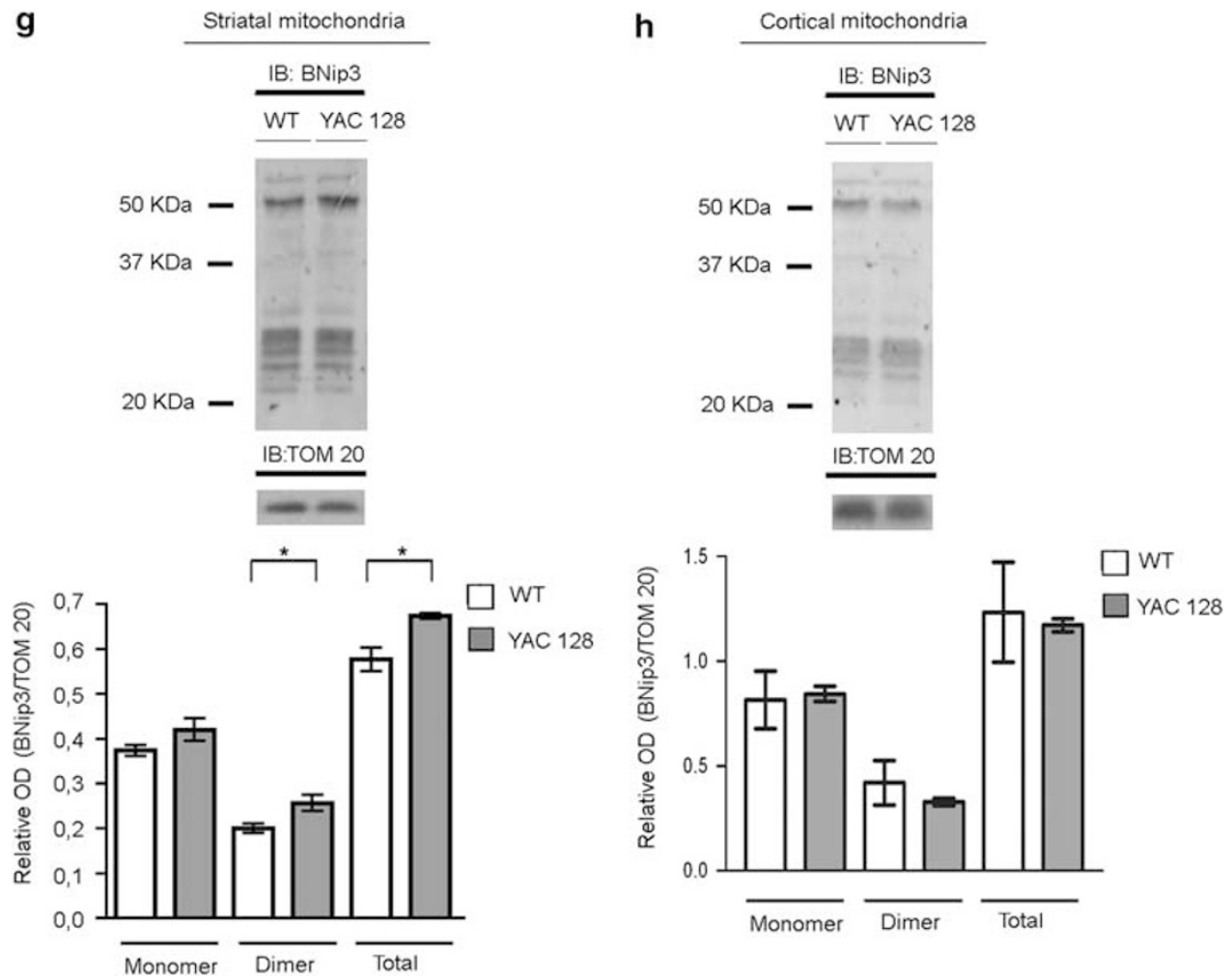

Figure 2 Continued

and mutant htt were similarly expressed in HEK293T cells (Figure 3d, left panel). An antibody recognizing expanded poly-Q tracts confirmed the expression of mutant htt (Figure 3d, right panel). HEK293T cells transfected with mutant htt had higher levels of monomeric and dimeric BNip3 than did HEK293T-htt-wt cells (Figure 3e, left panel). These results confirm the fact that the BNip3 protein undergoes accumulation and dimerization in cells expressing mutant htt. Truncated BNip3 $\Delta \mathrm{TM}$ protein did not dimerize (Figure $3 \mathrm{e}$, right panel) either in HEK293T-htt-wt or in HEK293T-htt-mut cells; indeed, BNip3 $\triangle T M$ was detected as two bands of $\sim 28 \mathrm{kDa}$, as previously shown. ${ }^{26}$ These data are in agreement with previous reports showing that the transmembrane domain of BNip3 is required for its dimerization..$^{20,26}$

We also analyzed alkali-treated mitochondrial fractions. HEK293T-htt-mut cells had higher BNip3 signals in their mitochondria than did HEK293T-htt-wt cells (Figure 3f). Both monomeric and dimeric BNip3 significantly increased in cells expressing mutated htt. BNip3 $\Delta \mathrm{TM}$ was not detected in mitochondrial fractions, in agreement with previous reports showing that the transmembrane domain of BNip3 is required for its complete integration into the mitochondrial membrane. ${ }^{20}$

Increased resistance of monomeric BNip3 in HD samples to proteinase-K digestion. One proposed model to explain BNip3 function posits that BNip3 can exist as an inactive, latent monomer, which requires a death activation signal to become active. ${ }^{28}$ The death signal elicits a conformational change in monomeric BNip3 that promotes protein dimerization or oligomerization in the lipid environment of the mitochondrial membrane and the formation of an ion-permeable channel through the OMM. ${ }^{25}$ Thus, a conformational change in the monomeric form is believed to be the triggering event in BNip3 activation and mitochondrial membrane permeabilization. To assess potential differences in the conformational state of monomeric BNip3 induced by mutant htt, we tested BNip3 resistance to in vitro digestion with proteinase-K $(P K)$ in whole extracts of HD samples. This approach has been successfully used to discriminate between inactive (more prone to digestion) and active (more resistant) forms of monomeric BNip3 in a previous study. ${ }^{14}$ The increased resistance of the active monomeric form to $\mathrm{PK}$ digestion is presumably due to the acquisition of a proteolysis-resistant conformation. ${ }^{14}$ Total lysates prepared from control and HD myoblasts were digested with increasing concentrations of $\mathrm{PK}$, and the products were analyzed by immunoblotting. As shown in Figure 4a, BNip3 monomers in cell lysates from HD myoblasts were significantly more resistant to $\mathrm{PK}$ digestion than those from control samples. Actin digestion was not different between HD and control samples (Figure 4a), demonstrating that the increased resistance to proteolysis in HD samples was specific for the BNip3 protein. Similar results were obtained using total protein extracts from $R 6 / 2$ and control mouse brains (Figure 4b). Overall, our data support the hypothesis that mutant htt promotes a conformational change in the BNip3 protein that may trigger its activation. To further confirm that BNip3 activation on mutated htt involve a posttrascriptional mechanism, we analyzed the transcriptional expression 


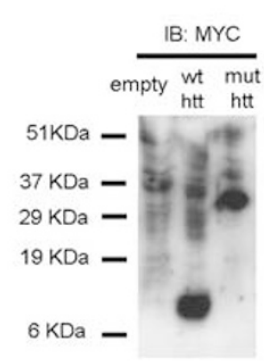

b

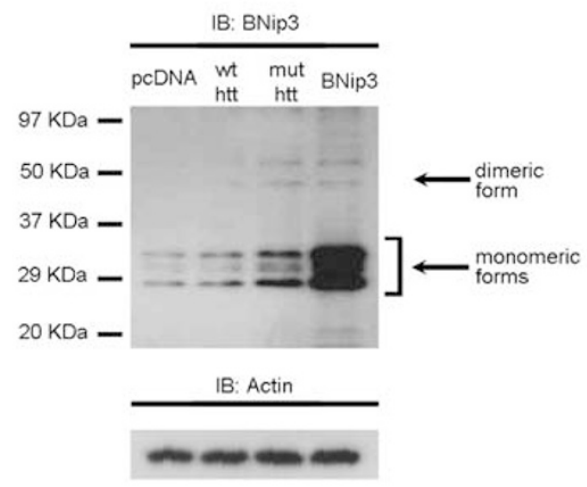

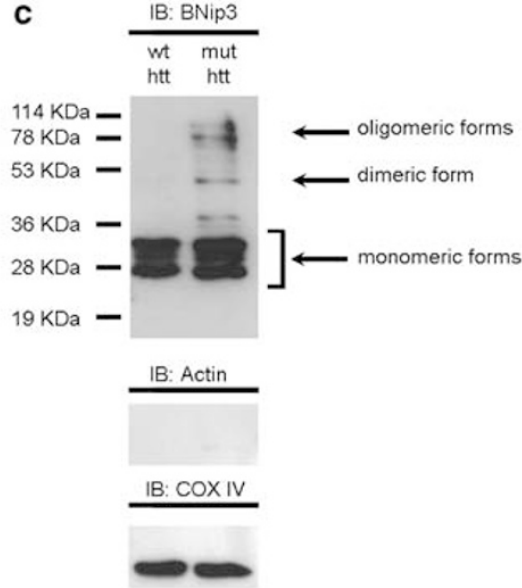
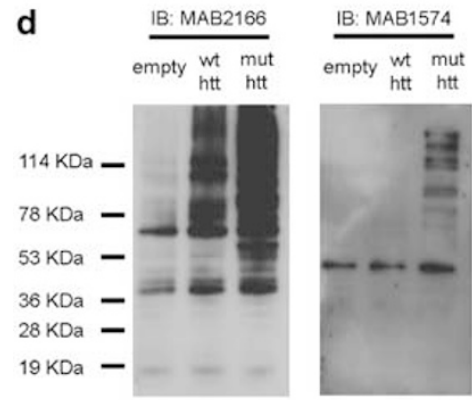

IB: Actin
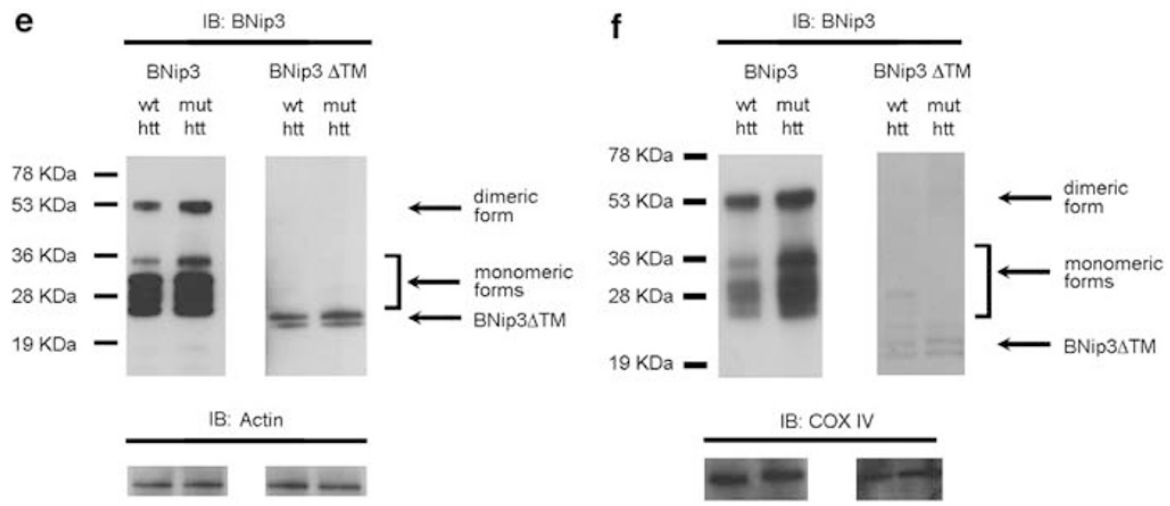

IB: COXIV

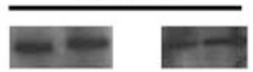

Figure 3 Analysis of BNip3 levels in cell culture models expressing mutant htt. (a) WB analysis of whole-protein extracts from SHSY5Y cells transiently transfected with pcDNA4 (lane 1), wild-type htt exon1-9CAG (lane 2) or mutated htt exon1-60CAG (lane 3) and harvested $72 \mathrm{~h}$ after transfection. The WB was probed with anti-Myc antibody (both wild-type and mutant htt exon-1 were tagged C-terminally with Myc epitopes). (b) WB analysis of SHSY5Y cells transiently transfected with empty vector (lane 1), wildtype htt exon1-9CAG (lane 2) or mutant htt exon1-60CAG (lane 3). Cells were harvested $72 \mathrm{~h}$ after transfection. The signals corresponding to monomeric and dimeric BNip3 (Clone ANa40) were higher in cells expressing mutant htt than in those expressing wild-type htt. Results are representative of three independent experiments. To verify the specificity of the signal, SHSY5Y cells were transfected with a plasmid encoding BNip3 (lane 4). Results are representative of three independent experiments. (c) Equal amounts of protein from alkali-treated mitochondrial fractions of SHSY5Y cells expressing wild-type htt exon1-9CAG (lane 1) or mutant htt exon1-60CAG (lane 2) were analyzed by WB and probed with anti-BNip3 antibody (Clone ANa40). To verify equal protein loading, membranes were stripped and reprobed with anti-actin and anti-COX IV antibodies. Results are representative of three independent experiments. (d) WB analysis of HEK293T cells transiently transfected with empty pcMV6NEO (lane 1), wild-type full-length htt-17CAG (lane 2) or mutant full-length htt-47CAG (lane 3). Blots were probed with anti-htt (MAB2166) and anti-poly-glutamine (MAB1574) antibodies. (e) WB analysis of HEK293T cells transiently cotransfected with wild-type full-length htt-17CAG and BNip3 (left panel, lane 1); mutant full-length htt-47CAG and BNip3 (left panel, lane 2); wild-type full-length htt-17CAG and BNip3 $\triangle \mathrm{TM}$ (right panel, lane 3); or mutant full-length htt-47CAG and BNip3 $\Delta \mathrm{TM}$ (right panel, lane 4). The signals corresponding to monomeric and dimeric BNip3 were higher in cells expressing mutant htt than in those expressing wild-type htt. Results are representative of three independent experiments. (f) Equal amounts of protein from alkali-treated mitochondrial fractions were analyzed by WB and probed with anti-BNip3 antibody (Clone ANa40). HEK293T cells were transiently transfected with wild-type full-length htt-17CAG and BNip3 (left panel, lane 1); mutated full-length htt-47CAG and BNip3 (left panel lane 2); wild-type full-length htt-17CAG and BNip3 $\triangle T M$ (right panel, lane 1); or mutant full-length htt-47CAG and BNip3 $\Delta$ TM (right panel, lane 2). To verify equal protein loading, blots were stripped and reprobed with anti-COX IV antibodies. Results are representative of three independent experiments

level of BNip3. Results are reported in Supplementary Figure 3. A slight increase in BNip3 mRNA was detected in HD myoblasts compared with control myoblasts. No difference in BNip3 mRNA was detected in R6/2 brains compared with brains of littermate controls, and in YAC128 brains compared with wild-type brains.

Overexpression of the mutant protein BNip3 $\Delta \mathrm{TM}$ and silencing of endogenous BNip3 protect cells from the mitochondrial depolarization induced by mutant htt. We have previously shown that human HD myoblasts show important features of mitochondrial dysfunction, with $\Delta \psi_{\mathrm{m}}$ decreased by $\sim 30 \%$ compared with control myoblasts. ${ }^{8}$ As BNip3 integration into the OMM can elicit the reduction of $\Delta \psi_{\mathrm{m}}$ on various toxic stimuli, ${ }^{15}$ we hypothesized that the high BNip3 levels we found associated with mitochondrial membrane fractions in HD cells could cause a decrease in $\Delta \psi_{\mathrm{m}}$, previously observed in HD myoblasts and other HD models. ${ }^{6,8,10,11}$

In this context, we reasoned that blocking both BNip3 integration in the OMM and BNip3 dimerization by overexpression of the dominant-negative protein BNip3 $\Delta \mathrm{TM}$ 


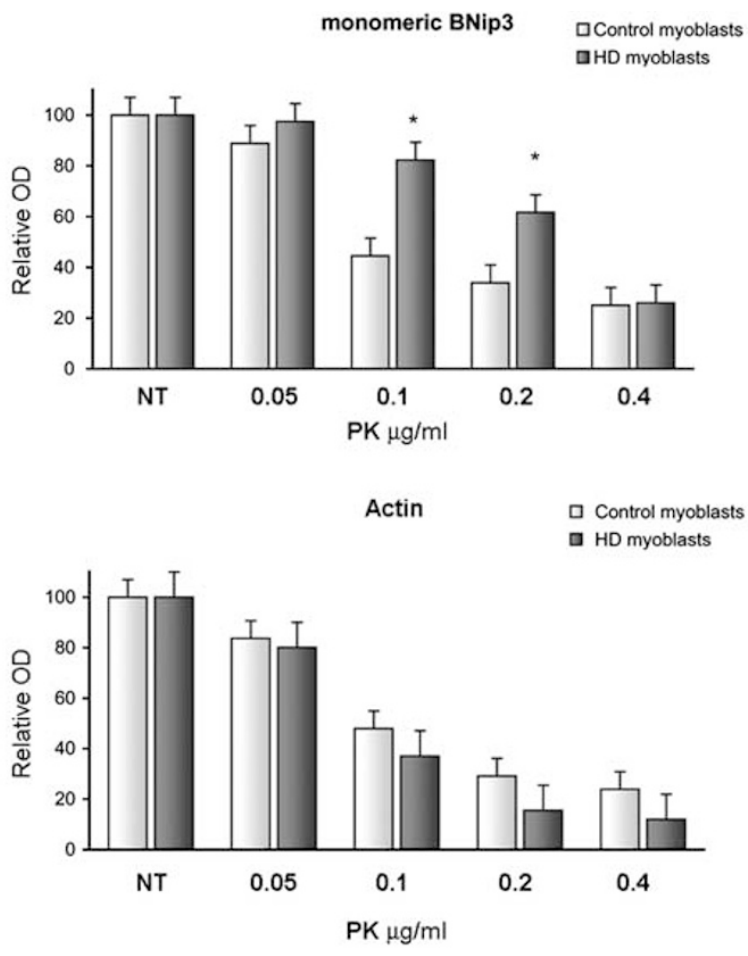

b

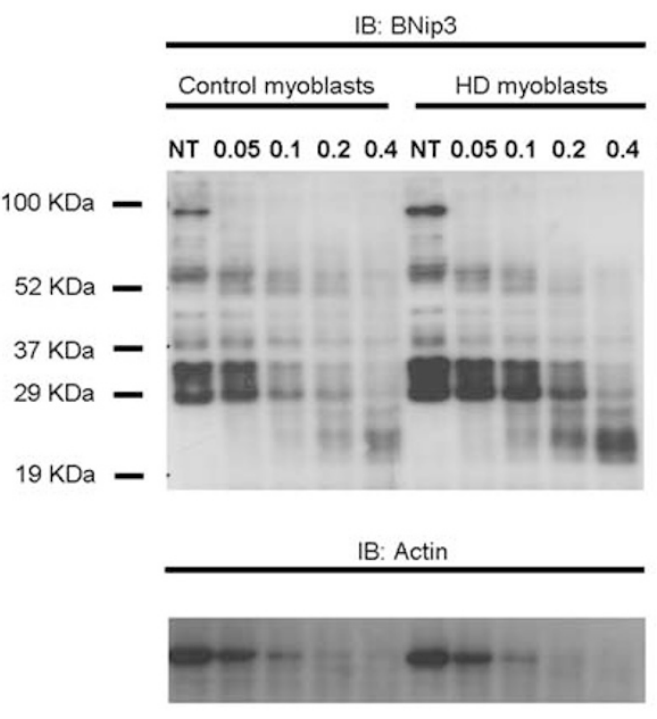

IB: BNip3

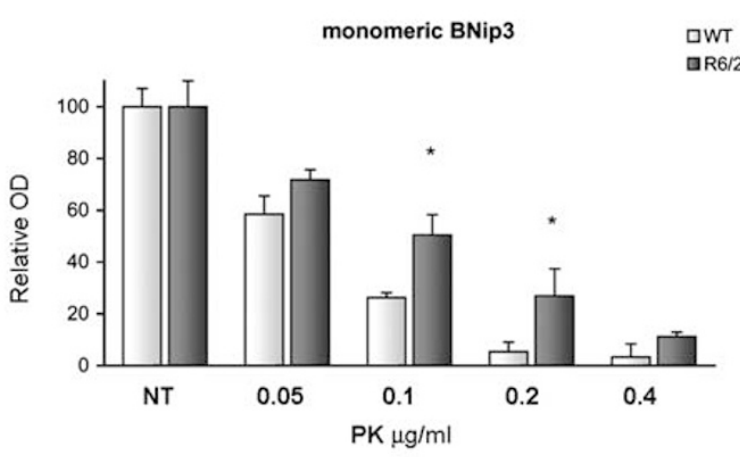

IB: Actin
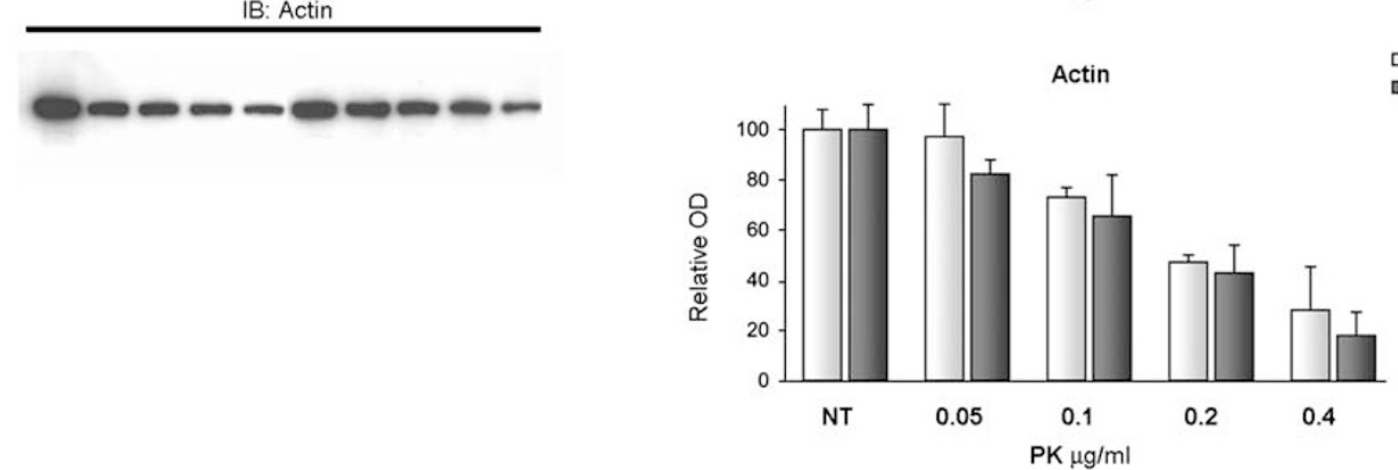

Figure 4 Increased resistance of monomeric BNip3 to proteinase-K digestion in HD cells. Total cell extracts from four human myoblasts (a) and three R6/2 mouse brains (b) were digested in vitro for $8 \mathrm{~min}$ with increasing concentrations of PK: $0.05 \mu \mathrm{g} / \mathrm{ml}$ (lane 2), $0.1 \mu \mathrm{g} / \mathrm{ml}$ (lane 3), $0.2 \mu \mathrm{g} / \mathrm{ml}$ (lane 4 ) and $0.4 \mu \mathrm{g} / \mathrm{ml}$ (lane 5); lane $1 \mathrm{contained} \mathrm{the}$ untreated sample. Lysis buffer contained $20 \mathrm{mM}$ Tris (pH 7.5), $150 \mathrm{mM} \mathrm{NaCl}, 1 \mathrm{mM}$ EDTA, $1 \%$ Triton X-100, $1 \mu \mathrm{g} / \mathrm{ml}$ pepstatin, $1 \mu \mathrm{g} / \mathrm{ml}$ leupeptin and $20 \mu \mathrm{M}$ MG132. Densitometric analysis was performed on monomeric BNip3 signals (Clone ANa40). Multiple bands corresponding to monomeric forms were analyzed together. Data are reported as means \pm S.E.M., as percentages of the untreated sample. Monomeric BNip3 extracted from HD samples demonstrated increased resistance to PK digestion $\left({ }^{*} P<0.05\right.$ versus control sample). No difference in actin digestion patterns was detected between HD and control samples

would protect cells from the mitochondrial depolarization induced by mutant htt. The mutant BNip3 $\Delta T M$ lacks the $\mathrm{C}$-terminal domain essential for integration into the OMM and has been shown to function as a dominant-negative mutant that blocks BNip3 translocation and integration into the OMM. ${ }^{22,23}$ 
a

IB: BNip3

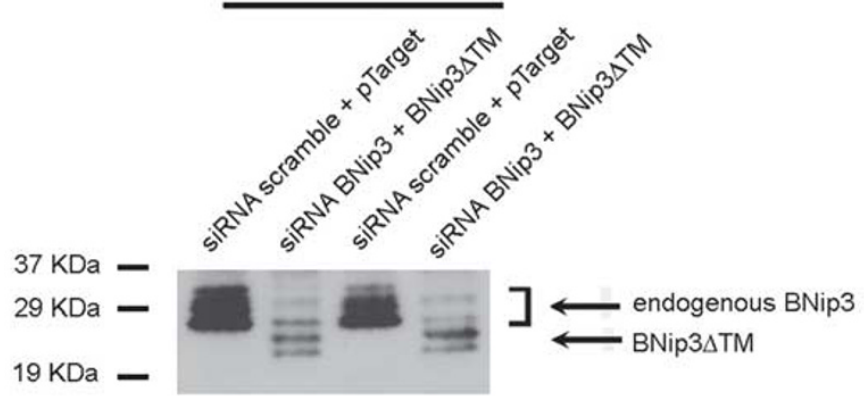

IB: Actin

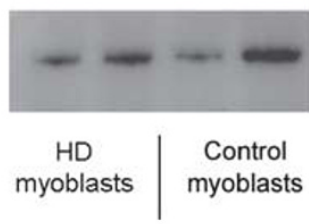

b

siRNA scramble + pTarget

口 siRNA BNip3 + BNip3 $\triangle$ TM

口 siRNA scramble + pTarget

口 siRNA BNip3 + BNip3 $\Delta$ TM

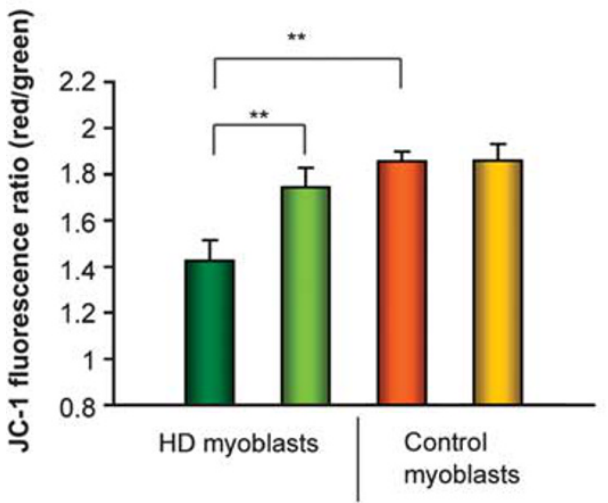

c

$\square$ siRNA scramble + pTarget

口siRNA BNip3 + BNip3ATM

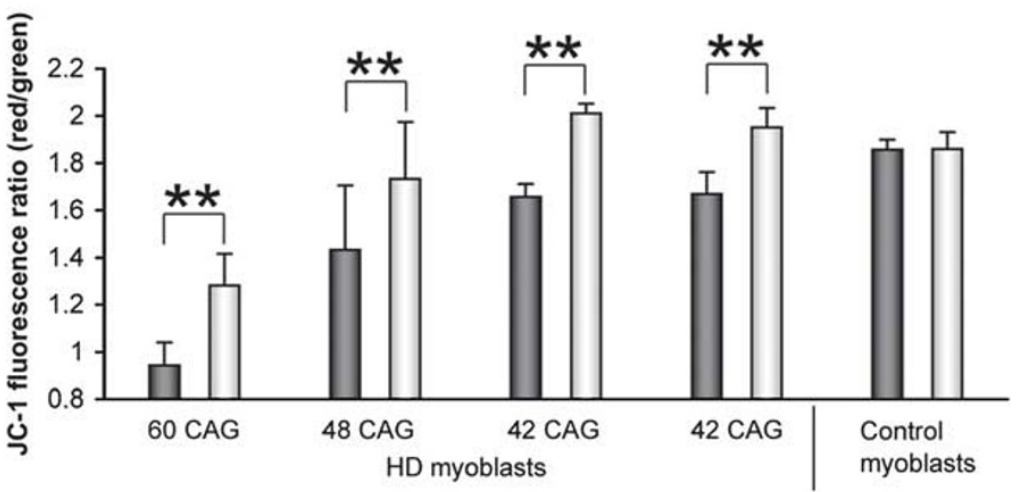

Figure 5 Overexpression of the mutant protein BNip3 $\Delta$ TM and silencing of endogenous BNip3 protect cells from mitochondrial depolarization. (a) WB analysis (Clone ANa40) of cotransfected myoblasts: lines 1 and 3 correspond to scrambled siRNA + empty pTarget; lines 2 and 4 correspond to BNip3 siRNA + BNip3 $\Delta$ TM. (b) Analysis of $\Delta \psi_{\mathrm{m}}$ in human $\mathrm{HD}$ (four samples) and control (four samples) myoblasts after treatment with siRNA against BNip3, together with a plasmid encoding BNip3 $\Delta \mathrm{TM}$. Data are presented as means \pm S.E.M. ( $\left.{ }^{\star \star} P<0.01\right)$. Cultured cells were transfected with equal amounts of plasmid DNA. (c) Image reports of the singular $\Delta \psi_{\mathrm{m}}$ values of HD muscular cell cultures from the four patients analyzed, carrying $60,48,42$ and $42 \mathrm{CAG}$ repeats, respectively. $\Delta \psi_{\mathrm{m}}$ values are reported as means \pm S.E.M. ( ${ }^{* \star} P<0.01$ ). Data were derived from three experiments performed on four $\mathrm{HD}$ and four control myoblast cultures

In human HD myoblasts, transient transfection with BNip3 $\Delta$ TM did not modify mitochondrial $\Delta \psi_{\mathrm{m}}$ both in control and HD myoblasts (data not shown), probably because of high endogenous levels of BNip3 and the low transfection efficiency of plasmid DNA in primary myoblasts ( $\sim 60 \%$ of cells displayed green fluorescence $24 \mathrm{~h}$ after trasfection with the pEGFP vector). However, cotransfection of cells with BNip3 $\Delta T M$ and with short interfering RNA (siRNA) to knock down endogenous BNip3 resulted in an efficient silencing of the endogenous protein (by $\sim 70 \%$, Figure $5 \mathrm{a}$ ), in a detectable expression of BNIP $3 \Delta \mathrm{TM}$, as well as in a significant increase in $\Delta \psi_{\mathrm{m}}$ in all four HD lines transfected (mean value $124 \%,{ }^{\star *} P<0.01$; Figures $5 \mathrm{~b}$ and $\mathrm{c}$ ).
Overall, these results suggest that the $\Delta \psi_{\mathrm{m}}$ loss in HD myoblasts may stem from BNip3 activation.

\section{Discussion}

Evidence that accrued over the past few years increasingly favors the hypothesis that mitochondrial dysfunction has a key function in the death of the neuronal cells of HD patients. ${ }^{34,35}$ Nevertheless, the nature of such mitochondrial damage has remained elusive so far. Our results suggest a role of BNip3 protein in the mitochondrial dysfunction induced by mutated htt. 
Clinical and experimental studies have provided convincing evidence that mitochondrial dysfunction occurs in the CNS and skeletal muscle tissue of HD patients. ${ }^{4,34,36,37}$ Thus, cultures of human myoblasts obtained from HD patients are an excellent model to study the pathogenic effects of mutated htt on the mitochondria. Our former study showed a pathological decrease of $\Delta \psi_{\mathrm{m}}$ in HD myoblasts. ${ }^{8}$ In this study, we provide evidence that BNip3 levels are increased in total lysates of HD myoblasts. More importantly, we demonstrate that more BNip3 colocalized with the mitochondria in human HD myoblasts when compared with age-matched control myoblasts. The increased total level of the BNip3 protein might depend both on transcriptional and on posttranscriptional regulation. However, results indicating increased BNip3 translocation into the mitochondria and BNip3 integration into the $\mathrm{OMM}$ in $\mathrm{HD}$ cells suggest that posttranscriptional mechanisms are primarily involved. This hypothesis is further supported by the finding that the BNip3 protein in HD myoblasts is more resistant to $\mathrm{PK}$ digestion compared with that in control samples, probably because of the acquisition of an alternative conformation as a prelude to BNip3 activation. ${ }^{14}$

The results obtained from human HD myoblasts were confirmed in the brain tissue extracted from two different animal models of HD, R6/2 and YAC128 mice. In both animal models, we observed increased levels of dimeric BNip3 associated with striatal mitochondrial fractions. Importantly, YAC128 mice showed increased BNip3 levels in the striatum at 6 months of age when, in spite of overt motor symptoms, no striatal tissue loss had yet occurred. This suggests that alterations in BNip3 localization and activity may precede neural loss in HD. In addition, the transient expression of mutant htt in SHSY5Y cells induced BNip3 accumulation and translocation into the OMM, thus confirming that this phenomenon occurs in neuronal cells and is directly triggered by mutant htt. Unfortunately, a study on BNip3 in human HD brains cannot be conducted, as BNip3 expression and activation are strongly induced by hypoxic conditions that inevitably precede the collection of autopsy specimens.

A large number of studies using cell culture models have shown that BNip3 integration into the OMM leads to a potential loss of mitochondria. ${ }^{19,21,23,38}$ In accordance with those results, a recent report described the spatial structure of BNip3 in a membrane-mimicking lipid environment, showing that BNip3 homodimers can form an ion-conducting pathway in the membrane. ${ }^{25}$ In line with these studies, BNip3 translocation into the mitochondrial membrane and BNip3 dimerization may elicit the $\Delta \psi_{\mathrm{m}}$ loss observed in animal and cell culture models of $\mathrm{HD}$ and in myoblasts extracted from HD patients.

We observed increased levels of BNip3 homodimers in the mitochondrial fractions of all HD models investigated in our studies, including human HD myoblasts, R6/2 and YAC 128 mouse brains and transfected cell lines. These data suggest that BNip3 dimerization may be a crucial step in the BNip3 activation process induced by mutant htt expression, even if a role for the monomeric form of BNip3 in mitochondrial damage cannot be ruled out. Indeed, we observed a significant accumulation of BNip3 monomers in SHSY5Y cells on mutant htt expression. Moreover, an increased resistance of the
BNip3 monomeric form to PK digestion was observed in lysates from R6/2 brains and HD myoblasts. Whether some of these monomers were derived from partial dissociation of the homodimers under denaturing and reducing conditions or rather represented the molecular precursors of dimers cannot be assessed.

If our hypothesis positing that BNip3 has a role in $\Delta \psi_{\mathrm{m}}$ loss in $\mathrm{HD}$ is correct, then the inhibition of BNip3 expression and/or BNip3 translocation and dimerization in HD cells should result in the increase in mitochondrial $\Delta \psi_{\mathrm{m}}$. BNip3 $\Delta \mathrm{TM}$ is a dominant-negative mutant lacking the transmembrane domain required for $\mathrm{BNip3}$ translocation and integration into the OMM. ${ }^{23,24}$ We observed that expression of BNip3 $\Delta T M$ and simultaneous downregulation of endogenous BNip3 by RNA interference in human HD muscle cells rescued the $\Delta \psi_{\mathrm{m}}$ loss induced by mutant htt. These data support a role for BNip3 in htt-induced mitochondrial damage and point to a new potential gene therapy approach for HD. It is important to note that BNip3 knockout mice are viable and lack a pathological phenotype; ${ }^{39}$ thus, the inhibition of BNip3 function by RNA interference or by overexpression of the dominant-negative mutant BNip3 $\Delta$ TM may have neuroprotective effects without causing adverse side effects.

One question that remains unanswered is how mutant htt induces BNip3 activation. Previous reports have shown that BNip3 association with mitochondria is strongly stabilized by acidosis $^{14,40}$ or by an increased cytosolic calcium concentration. ${ }^{18}$ Both conditions may occur in HD cells, causing BNip3 stabilization and integration into the OMM, but one more intriguing possibility should also be considered: in light of the fact that htt can localize to the mitochondria by loosely associating with the OMM, we may hypothesize that htt binds directly or indirectly to BNip3. Future studies will aim at elucidating these and other potential mechanisms underlying the effects of mutant htt on BNip3.

\section{Materials and Methods}

Muscle cell cultures. Muscle cell cultures were obtained from human biopsy specimens, as described previously. ${ }^{8}$ Demographic and clinical data of HD patients and control subjects are reported in Supplementary Table 1.

Animal models. Transgenic R6/2 mice and wild-type CBA animals were originally obtained from the Jackson Laboratory (Bar Harbor, ME, USA) and from a colony established in the animal facility of the Department of Biomolecular Science and Biotechnology, University of Milan. Two additional R6/2 mouse brains were kindly donated by Dr. Ferdinando Squitieri (IRCCS Neuromed, Pozzilli (IS)). YAC128 mice (FVB-Tg(YAC128)53Hay/J) were originally obtained from the Jackson Laboratory and maintained in the Health Sciences Laboratory Animal Services at the University of Alberta. All mice were handled following institutional guidelines.

Plasmids. Plasmids encoding Myc-tagged htt exon-1, wild-type (9 CAG) or mutant (60 CAG), were generated by in-frame insertion of a PCR-amplified DNA fragment encoding htt exon-1 into the pcDNA4-Myc-HIS vector (Invitrogen, Carlsbad, CA, USA). Plasmid pTarget-BNip3 $\triangle T$ TM was created by introducing a stop codon (TAG) after amino acid 161, using the QuikChange kit (Stratagene, La Jolla, CA, USA). To prevent BNip3 $\triangle$ TM from being silenced by siRNA against endogenous BNip3, three conservative single-nucleotide mutations were introduced (i.e., a468c, c471t and a477c).

All DNA constructs were verified by sequencing with the BigDye Terminator kit (Applied Biosystems, Foster City, CA, USA).

Isolation of mitochondria and immunoblotting. Cells were homogenized with 40 strokes in a $1 \mathrm{ml}$ Dounce homogenizer and centrifuged at 
$600 \times g$ for 5 min to pellet nuclei and cell debris. The supernatant was centrifuged at $10000 \times g$ for $20 \mathrm{~min}$ to obtain the mitochondria-enriched pellet. Mitochondria fractions were incubated on ice for 30 min with $100 \mathrm{mM} \mathrm{Na}_{2} \mathrm{CO}_{3}$ and centrifuged at $75000 \times g$ to collect mitochondrial transmembrane proteins.

Mitochondrial isolation from mouse brains was performed as follows: Fresh tissues (striatum and cortex) were washed with cold PBS and homogenized by 25 strokes in a Dounce homogenizer in a buffer containing $50 \mathrm{mM}$ HEPES (pH 7.5), $1 \mathrm{mM}$ mannitol, $350 \mathrm{mM}$ sucrose and $5 \mathrm{mM}$ EGTA. Intact cells and nuclei were separated by centrifugation at $1000 \times g$ for $5 \mathrm{~min}$, and supernatants were centrifuged at $3500 \times g$ for $10 \mathrm{~min}$ to collect mitochondrial pellets. The mitochondrial pellets were incubated on ice for 30 min with $100 \mathrm{mM} \mathrm{Na}_{2} \mathrm{CO}_{3}$, then centrifuged at $75000 \times g$ to collect the heavy mitochondrial membrane pellets.

Equal amounts of protein were resolved on $12 \%$ SDS-PAGE gels. Antibodies for htt protein (MAB2166) and for expanded poly-Q (MAB1574) were purchased from Chemicon International (Billerica, MA, USA). Anti-Cox IV was obtained from Cell Signaling. Anti-BNip3 antibodies were from Cell Signaling (Danvers, MA, USA) and Sigma (St Louis, MO, USA). The anti-TOM20 antibody was a gift from Dr. Goping (University of Alberta, Edmonton, Alberta, Canada). HRP-conjugated antibodies were from GE Healthcare (Europe Gmbh, Milano, Italy). IR780- and IR800-conjugated antibodies were from Li-Cor (Li-Cor Biotechnology, Lincoln, $\mathrm{NE}$, USA). Protein detection was performed by enhanced chemiluminescence (GE Healthcare) or by using the Odyssey infrared imaging system (Li-Cor Biotechnology). Densitometric analysis of chemiluminescent protein bands was performed using Quantity One Software (BioRad, Hercules, CA, USA).

Transfection assays. SHSY5Y cells were transfected using Lipofectamine 2000 reagent (Invitrogen), according to the manufacturer's protocol. SHSY5Y cells were then differentiated with $10 \mu \mathrm{M}$ retinoic acid (Sigma) and harvested $72 \mathrm{~h}$ after transfection.

Human myoblasts were plated in 6- or 96-well plates and transfected in Optimem using Lipofectamine 2000, $0.8 \mu \mathrm{g} / \mathrm{ml}$ plasmid DNA and $40 \mathrm{nM}$ siRNA. Stealth RNA oligonucleotides (siRNA) against human BNip3 were purchased from Invitrogen. The transfection efficiency of siRNA $(>80 \%)$ was confirmed with Block-iT Fluorescent Oligo, as described previously.

Mitochondrial potential $\left(\Delta \psi_{\mathrm{m}}\right)$. Mitochondrial potential was evaluated using a microfluorimetry assay, as described previously. ${ }^{8}$ Fluorescence intensity was monitored with a fluorescence plate reader (Ascent FL Thermo Labsystems, Waltham, MA, USA), using two excitation and emission filters (485/530 and 530/ 590). The results are reported as ratios of red/green fluorescence.

Immunofluorescence. Cell monolayers were labeled with $250 \mathrm{nM}$ MitoTrackerRed for $30 \mathrm{~min}$ at $37^{\circ} \mathrm{C}$, then fixed in $4 \%$ paraformaldehyde, permeabilized with $0.5 \%$ Triton X-100, thoroughly washed and finally blocked with $10 \%$ normal goat serum. Cells were incubated first with anti-BNip3 antibody (Prestige Antibodies, Stockholm, Sweden) at $4^{\circ} \mathrm{C}$, thoroughly washed and then incubated with Alexa Fluor 488 anti-rabbit (Invitrogen) for $1 \mathrm{~h}$. Slides were analyzed with an LSM510 laser scanning confocal microscope mounted on a Zeiss Axiovert $100 \mathrm{M}$ microscope (Zeiss, Thornwood, NY, USA), using a $40 \times 1.3$ oil objective. Images were converted to tif files and cropped using Adobe Photoshop CS3 (Adobe, San Jose, CA, USA).

Statistical analysis. Unless otherwise stated, all data are expressed as means \pm S.E.M. Data were subjected to normality tests. As data showed normal distributions, we used a parametric ANOVA (analysis of variance), followed by Tukey's test, to detect significant differences among groups, unless otherwise stated. Statistical significance was set at $P<0.05$.

\section{Conflict of interest}

The authors declare no conflict of interest.

Acknowledgements. We thank the patients and their families for their support (Associazione 'Mauro Emolo' O.N.L.U.S.), Dr. Ing Swie Goping (University of Alberta) for providing anti-TOM20 antibodies and the personnel of the confocal facility at the Cross Cancer Institute (Edmonton, Canada) for technical assistance. We are grateful to Dr. Ferdinando Squitieri for providing two R6/2 brain tissue samples. We also gratefully acknowledge the financial support of the Italian Health Ministry (AC, Malattie Neurodegenerative Ex Art. 56 legge finanziaria 2004)

1. Gu M, Gash MT, Mann VM, Javoy-Agid F, Cooper JM, Schapira AH. Mitochondrial defect in Huntington's disease caudate nucleus. Ann Neurol 1996; 39: 385-389.

2. Tabrizi SJ, Cleeter MW, Xuereb J, Taanman JW, Cooper JM, Schapira AH. Biochemical abnormalities and excitotoxicity in Huntington's disease brain. Ann Neurol 1999; 45: 25-32.

3. Seong IS, Ivanova E, Lee JM, Choo YS, Fossale E, Anderson M et al. HD CAG repeat implicates a dominant property of Huntingtin in mitochondrial energy metabolism. Hum $\mathrm{Mol}$ Genet 2005; 14: 2871-2880.

4. Saft C, Zange J, Andrich J, Müller K, Lindenberg K, Landwehrmeyer B et al. Mitochondrial impairment in patients and asymptomatic mutation carriers of Huntington's disease. Mov Disord 2005; 20: 674-679.

5. Squitieri F, Cannella M, Sgarbi G, Maglione V, Falleni A, Lenzi $P$ et al. Severe ultrastructural mitochondrial changes in lymphoblasts homozygous for Huntington disease mutation. Mech Ageing Dev 2006; 127: 217-220.

6. Sawa A, Wiegand GW, Cooper J, Margolis RL, Sharp AH, Lawler Jr JF et al. Increased apoptosis of Huntington disease lymphoblasts associated with repeat length-dependent mitochondrial depolarization. Nat Med 1999; 5: 1194-1198.

7. Panov AV, Gutekunst CA, Leavitt BR, Hayden MR, Burke JR, Strittmatter WJ et al. Early mitochondrial calcium defects in Huntington's disease are a direct effect of polyglutamines. Nat Neurosci 2002; 5: 731-736.

8. Ciammola A, Sassone J, Alberti L, Meola G, Mancinelli E, Russo MA et al. Increased apoptosis, Huntingtin inclusions and altered differentiation in muscle cell cultures from Huntington's disease subjects. Cell Death Differ 2006; 13: 2068-2078.

9. Almeida $S$, Sarmento-Ribeiro $A B$, Januário $C$, Rego $A C$, Oliveira $C R$. Evidence of apoptosis and mitochondrial abnormalities in peripheral blood cells of Huntington's disease patients. Biochem Biophys Res Commun 2008; 374: 599-603.

10. Benchoua A, Trioulier Y, Zala D, Gaillard MC, Lefort N, Dufour $\mathrm{N}$ et al. Involvement of mitochondrial complex II defects in neuronal death produced by $\mathrm{N}$-terminus fragment of mutated Huntingtin. Mol Biol Cell 2006; 17: 1652-1663.

11. Bae $\mathrm{Bl}, \mathrm{Xu} \mathrm{H}$, Igarashi $\mathrm{S}$, Fujimuro $\mathrm{M}$, Agrawal $\mathrm{N}$, Taya $\mathrm{Y}$ et al. p53 mediates cellular dysfunction and behavioral abnormalities in Huntington's disease. Neuron 2005; 47: $29-41$.

12. Panov AV, Burke JR, Strittmatter WJ, Greenamyre JT. In vitro effects of polyglutamine tracts on $\mathrm{Ca} 2+-$ dependent depolarization of rat and human mitochondria: relevance to Huntington's disease. Arch Biochem Biophys 2003; 410: 1-6.

13. Harris $\mathrm{MH}$, Thompson $\mathrm{CB}$. The role of the Bcl-2 family in the regulation of outer mitochondrial membrane permeability. Cell Death Differ 2000; 7: 1182-1191.

14. Frazier DP, Wilson A, Graham RM, Thompson JW, Bishopric NH, Webster KA. Acidosis regulates the stability, hydrophobicity, and activity of the BH3-only protein Bnip3. Antioxid Redox Signal 2006; 8: 1625-1634.

15. Lee H, Paik SG. Regulation of BNIP3 in normal and cancer cells. Mol Cells 2006; 21: 1-6.

16. Burton TR, Henson ES, Baijal P, Eisenstat DD, Gibson SB. The pro-cell death Bcl-2 family member, BNIP3, is localized to the nucleus of human glial cells: implications for glioblastoma multiforme tumor cell survival under hypoxia. Int J Cancer 2006; 118: 1660-1669.

17. Webster KA, Graham RM, Bishopric NH. BNip3 and signal-specific programmed death in the heart. J Mol Cell Cardiol 2005; 38: 35-45.

18. Graham RM, Thompson JW, Wei J, Bishopric NH, Webster KA. Regulation of Bnip3 death pathways by calcium, phosphorylation, and hypoxia-reoxygenation. Antioxid Redox Signal 2007: 9: 1309-1315.

19. Vande Velde C, Cizeau J, Dubik D, Alimonti J, Brown T, Israels S et al. BNIP3 and genetic control of necrosis-like cell death through the mitochondrial permeability transition pore. Mol Cell Biol 2000; 20: 5454-5468.

20. Ray R, Chen G, Vande Velde C, Cizeau J, Park JH, Reed JC et al. BNIP3 heterodimerizes with $\mathrm{Bcl}-2 / \mathrm{Bcl}-\mathrm{X}(\mathrm{L})$ and induces cell death independent of a $\mathrm{Bcl}-2$ homology 3 $(\mathrm{BH} 3)$ domain at both mitochondrial and nonmitochondrial sites. J Biol Chem 2000; 275: 1439-1448.

21. Kim JY, Cho JJ, Ha J, Park JH. The carboxy terminal C-tail of BNip3 is crucial in induction of mitochondrial permeability transition in isolated mitochondria. Arch Biochem Biophys 2002; 398: 147-152.

22. Hamacher-Brady A, Brady NR, Logue SE, Sayen MR, Jinno M, Kirshenbaum LA et al. Response to myocardial ischemia/reperfusion injury involves Bnip3 and autophagy. Cell Death Differ 2007; 14: 146-157.

23. Kubasiak LA, Hernandez OM, Bishopric NH, Webster KA. Hypoxia and acidosis activate cardiac myocyte death through the Bcl-2 family protein BNIP3. Proc Natl Acad Sci USA 2002; 99: 12825-12830.

24. Regula KM, Ens K, Kirshenbaum LA. Inducible expression of BNIP3 provokes mitochondrial defects and hypoxia-mediated cell death of ventricular myocytes. Circ Res 2002; 91: 226-231.

25. Bocharov EV, Pustovalova YE, Pavlov KV, Volynsk PE, Goncharuk MV, Ermolyuk YS et al. Unique dimeric structure of BNip3 transmembrane domain suggests membrane permeabilization as a cell death trigger. J Biol Chem 2007; 282: 16256-16266.

26. Chen G, Ray R, Dubik D, Shi L, Cizeau J, Bleackley RC et al. The E1B 19K/Bcl-2-binding protein Nip3 is a dimeric mitochondrial protein that activates apoptosis. J Exp Med 1997; 186: $1975-1983$ 
27. Mellor HR, Harris AL. The role of the hypoxia-inducible BH3-only proteins BNIP3 and BNIP3L in cancer. Cancer Metastasis Rev 2007; 26: 553-566.

28. Tracy K, Macleod KF. Regulation of mitochondrial integrity, autophagy and cell survival by BNIP3. Autophagy 2007; 3: 616-619.

29. Goping IS, Gross A, Lavoie JN, Nguyen M, Jemmerson R, Roth $\mathrm{K}$ et al. Regulated targeting of BAX to mitochondria. J Cell Biol 1998; 143: 207-215.

30. Mangiarini L, Sathasivam K, Seller M, Cozens B, Harper A, Hetherington C et al. Exon 1 of the $\mathrm{HD}$ gene with an expanded $C A G$ repeat is sufficient to cause a progressive neurological phenotype in transgenic mice. Cell 1996; 87: 493-506.

31. Hodgson JG, Agopyan N, Gutekunst CA, Leavitt BR, LePiane F, Singaraja R et al. A YAC mouse model for Huntington's disease with full-length mutant Huntingtin, cytoplasmic toxicity, and selective striatal neurodegeneration. Neuron 1999; 23: 181-192.

32. Gao S, Fu W, Dürrenberger M, De Geyter C, Zhang H. Membrane translocation and oligomerization of $\mathrm{hBok}$ are triggered in response to apoptotic stimuli and Bnip3. Cell $\mathrm{Mol}$ Life Sci 2005; 62: 1015-1024.

33. Kothari S, Cizeau J, McMillan-Ward E, Israels SJ, Bailes M, Ens K et al. BNIP3 plays a role in hypoxic cell death in human epithelial cells that is inhibited by growth factors EGF and IGF. Oncogene 2003; 22: 4734-4744.

34. Browne SE. Mitochondria and Huntington's disease pathogenesis: insight from genetic and chemical models. Ann NY Acad Sci 2008; 1147: 358-382.

35. Bossy-Wetzel $E$, Petrilli $A$, Knott $A B$. Mutant Huntingtin and mitochondrial dysfunction. Trends Neurosci 2008; 31: 609-616.
36. Arenas J, Campos $\mathrm{Y}$, Ribacoba $\mathrm{R}$, Martín MA, Rubio JC, Ablanedo $\mathrm{P}$ et al Complex I defect in muscle from patients with Huntington's disease. Ann Neurol 1998; 43: 397-400.

37. Lodi R, Schapira AH, Manners D, Styles P, Wood NW, Taylor DJ et al. Abnormal in vivo skeletal muscle energy metabolism in Huntington's disease and dentatorubropallidoluysian atrophy. Ann Neurol 2000; 48: 72-76.

38. Kubli DA, Ycaza JE, Gustafsson AB. Bnip3 mediates mitochondrial dysfunction and cell death through Bax and Bak. Biochem J 2007; 405: 407-415.

39. Diwan A, Krenz M, Syed FM, Wansapura J, Ren X, Koesters AG et al. Inhibition of ischemic cardiomyocyte apoptosis through targeted ablation of Bnip3 restrains postinfarction remodeling in mice. J Clin Invest 2007; 117: 2825-2833.

40. Graham RM, Frazier DP, Thompson JW, Haliko S, Li H, Wasserlauf BJ et al. A unique pathway of cardiac myocyte death caused by hypoxia-acidosis. J Exp Biol 2004; 207: 3189-3200.
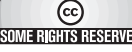

Cell Death and Disease is an open-access journal published by Nature Publishing Group. This article is licensed under a Creative Commons Attribution-Noncommercial-Share Alike 3.0 License. To view a copy of this license, visit http:/l creativecommons.org/licenses/by-nc-sa/3.0/

Supplementary Information accompanies the paper on Cell Death and Disease website (http://www.nature.com/cddis) 